\title{
Implementation of Performance Shaping Factor (PSF)-based Risk Assessment and Human Error Assessment and Reduction Technique (HEART) at the ITB Student Dormitory Building C and D Construction Project
}

\section{Niko Junianto and Katharina Oginawati}

Environmental Engineering Program, Faculty of Civil and Environmental Engineering, Institute of Technology Bandung, Bandung, Indonesia

\section{Abstract}

Construction sector is one of the main pillars in the economic development of the world, including Indonesia. However, the number of occupational accidents in the

Corresponding Author:

Niko Junianto

nikojunianto16@gmail.com

Received: 15 May 2018

Accepted: 3 June 2018

Published: 19 June 2018

Publishing services provided by Knowledge E

(c) Niko Junianto and Katharina Oginawati. This article is distributed under the terms of the Creative Commons

Attribution License, which permits unrestricted use and redistribution provided that the original author and source are credited.

Selection and Peer-review under the responsibility of the ICOHS 2017 Conference Committee. construction sector is still relatively high until now. 60 to 70 percent of occupational accidents in many employment sectors are caused by human errors. Therefore, the analysis of human error is important to be implemented. The objectives of this study were to know the stages/ types of work in the project with the greatest risk, to know the type of occupational accident with the highest HEP (human error probability), to know the main cause of human error occurred, as well as to know the implementation of health and safety in the project based on human error analysis performed. The methods used in this research were PSF (performance shaping factor)-based risk assessment and HEART (human error assessment and reduction technique). The research tools used for the primary data collection were interview and observation. Secondary data needed were occupational accidents data and work procedures from the project health and safety supervisor. Based on the PSF-based risk assessment method, it was known that the type of work with the highest risk occurred in the iron reinforcement welding to steel columns or beams (from columns and beams work and concrete canopy work), with the risk value of 24 (of 24), which resulted from fall from height hazard. While the HEART method showed that the fall from height accident had the highest HEP value (4.75) among any other accidents. The main cause of the human error occurred in the project was the absence of complete written procedures for workers. Based on the analysis performed, it could be known that the company needed to improve the implementation of health and safety in the project, which could be done systematically, started from the employers, safety supervisor, and workers.

\section{G OPEN ACCESS}

Keywords: construction, human error, PSF-based risk assessment, HEART method 


\section{Introduction}

The construction sector is one of the main contributors in the economic development of Indonesia. Nevertheless, the number of occupational accidents in the construction sector is still classified as high until now. Accidents and occupational diseases will be very detrimental to the company directly, either because of the cost or time loss. Therefore, it is vital to always prioritize the health and safety in a company [1].

60 to 70 percent of occupational accidents in various sectors are caused by human errors [2]. Human error is defined as inappropriate or undesirable human decision or behavior that reduces, or has the potential for reducing effectiveness, safety, or system performance [3]. Human error analysis is important to be performed. However, human error analysis in construction industry in Indonesia was still rarely done. One of studies related to the human error analysis in construction sector in Indonesia has been conducted by Awaludin [4] using the occupational accident data. Result of the study showed that the main cause of accidents occurred in the research was the tendency of workers to perform tasks hastily.

Generally, performance shaping factor (PSF) could be used to help clarifying the cause of human error and providing information to create practical solution [5]. PSF can be used to support the conventional risk assessment process. Thus, the resulted output of the risk assessment is more comprehensive, since it has involved human error in the analysis. PSF-based risk assessment is a human error analysis method which can be used for industries in general [6].

Another approach which can be used to perform the human error analysis is applying the human reliability analysis (HRA). This research was conducted with the quantitative approach of HRA using HEART (human error assessment and reduction technique) method. HEART method is a quick and simple method which can be applied to various situations or industries to calculate the HEP value $[7,8]$. In this research, HEART method was used to analyze the occupational accidents that had occurred in the project.

The objectives of this research were to know the groups/ types of work in the project which posed greatest risks based on the PSF-based risk assessment method, to know the type of occupational accident which had the highest HEP value based on the HEART method, to know the main cause of human error occurred, and to know the implementation of health and safety in the project based on human error analysis performed. 


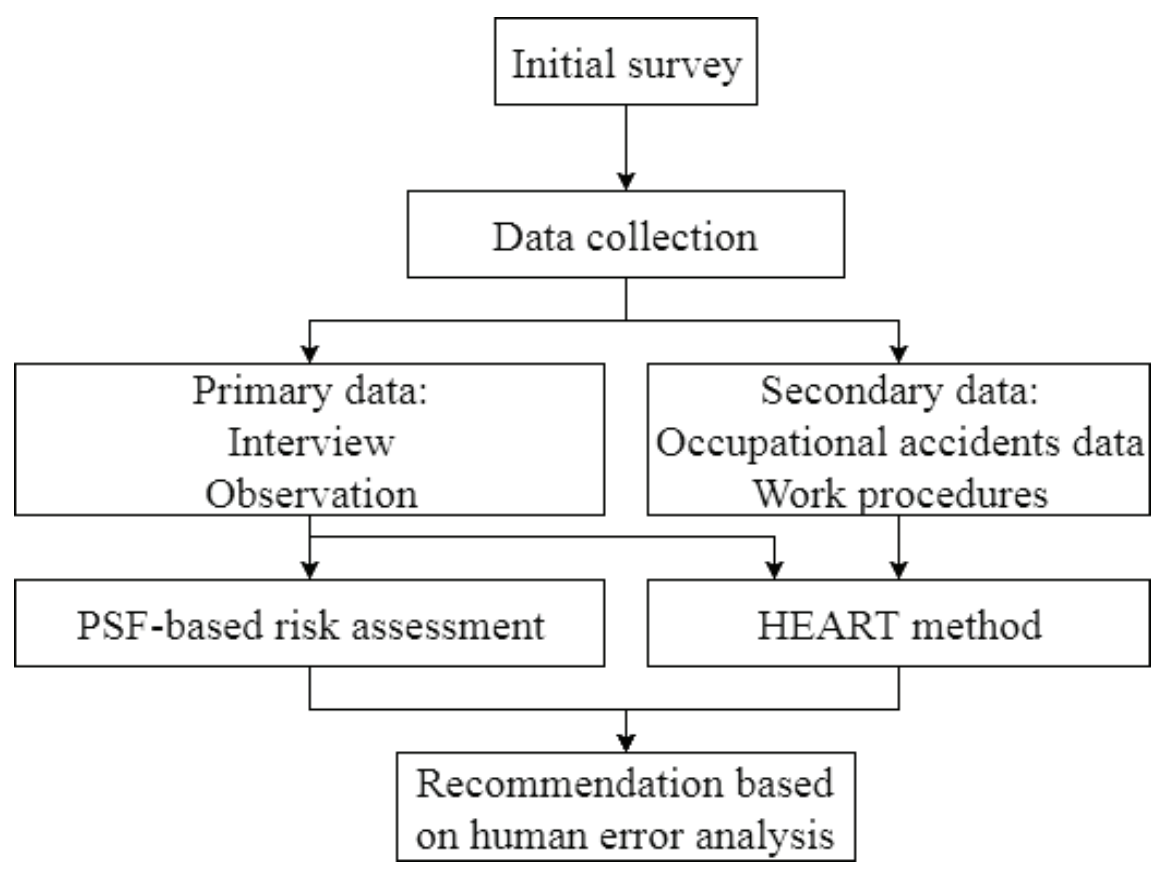

Figure 1: Research Scheme.

\section{Methods}

Research scheme is shown on Figure 1 below.

\subsection{Initial survey}

Research was conducted in the ITB student dormitory building C and D which located in Bandung, Indonesia. The initial survey was done to observe the research location and the specified work plan.

\subsection{Data collection}

The required data in the study included both primary and secondary data. The research tools used for primary data collection were observation and interview. The structured interview was conducted to the safety supervisor and workers in the project. 92 workers in the project were assigned as the respondents. Interview conducted to workers covered PSF criteria [6] that were experienced by them while performing their tasks. Interview conducted to the safety supervisor aimed at getting detailed information related to the occupational accidents in the project including GTTs (generic task types), 
EPCs (error producing conditions), and APOA (assessed proportion of affect) [8]. Secondary data needed covered the occupational accidents data during the construction project and work procedures.

\subsection{Analysis of PSF-based risk assessment}

Analysis of PSF-based risk assessment was started with counting and classifying the total PSF occurred on each task into three categories, which are insignificant, exist, and significant human error. The PSF value $(\mathrm{H})$ obtained was put into risk assessment quantification table to be calculated with other risk factors (consequency/ $C$, frequency/ $\mathrm{F}$, probability/ P). The risk quantification results obtained by summing up each value of aforementioned factors were classified into four categories, namely category IV (addition value 23-24), III (addition value 13-22), II (addition value 7-12), and I (addition value $<6)[6]$.

\subsection{Analysis of HEART}

Analysis of HEART aimed to know HEP value at each occupational accident that had occurred in the project. Analysis of HEART was started with classifying GTTs, identifying EPCS, and determining APOA based on the interview to the safety supervisor. The calculation of HEP value was done using the equation below [8].

$$
\mathrm{HEP}=\left[r \times \prod i p i(f i-1)+1\right]
$$

where:

HEP : Human error probability

r : GTT value

pi : APOA value

fi : Total effect from EPC

\subsection{Recommendations drafting}

Based on overall human error analysis performed, various recommendations could be produced in order to prevent the existence of human error in the project, which then could control the risk of hazards and prevent the occurrence of occupational accidents in the construction work. 
TABLE 1: Types of Work In The Unit of Architectural Work That Had Fall From Height Hazard Potentials and Belonged to Category IV Risk.

\begin{tabular}{|c|c|c|c|c|c|c|c|}
\hline $\begin{array}{l}\text { Sub-unit of } \\
\text { Architectural } \\
\text { Work }\end{array}$ & $\begin{array}{l}\text { Groups of } \\
\text { Work }\end{array}$ & Types of Work & C & $\mathbf{P}$ & $\mathbf{F}$ & H & $\begin{array}{l}\text { Risk } \\
\text { Value }\end{array}$ \\
\hline $\begin{array}{l}\text { Non-structural } \\
\text { concrete work }\end{array}$ & $\begin{array}{l}\text { Columns } \\
\text { and beams } \\
\text { work }\end{array}$ & $\begin{array}{l}\text { Installation of iron } \\
\text { reinforcement by } \\
\text { welding to steel columns } \\
\text { or beams }\end{array}$ & 10 & 6 & 4 & 4 & 24 \\
\hline $\begin{array}{l}\text { Non-structural } \\
\text { concrete work }\end{array}$ & $\begin{array}{l}\text { Concrete } \\
\text { canopy } \\
\text { work }\end{array}$ & $\begin{array}{l}\text { Installation of iron } \\
\text { reinforcement by } \\
\text { welding to steel columns } \\
\text { or beams }\end{array}$ & 10 & 6 & 4 & 4 & 24 \\
\hline
\end{tabular}

\section{Results}

\subsection{Analysis of PSF-based risk assessment}

Based on the evaluation of the PSF that has been done to the workers, various PSF criteria which occurred in every task were:

1. Criteria 2: SOP (standard operational procedure) full of inaccuracies, imperfect SOP, poor SOP;

2. Criteria 5: possible unsafe act, for instance not using any protective equipment;

3. Criteria 10: fatigue aspect.

Based on the analysis of PSF-based risk assessment performed, generally there were two hazard risks (0.1\%) of overall risks in ITB student dormitory building C and D construction project that belonged to the category IV risk (Table 1). While category III and II risks had percentage of $61.4 \%$ (1069 risks) and 38.5\% (670 risks) respectively.

\subsection{Analysis of HEART}

Based on the analysis of HEART performed to 53 occupational accidents data in the project, it could be known that the EPC which became the major cause of whole occupational accidents in the project was an improverished quality of information conveyed by procedures and person-person interaction. Koradecka [9] mentioned that the lack of procedures for working safely becomes one of the causes of accident in industry.

In this study, the overall number of EPCs found were 13 EPCs. Based on Kirwan [10], in general the average number of EPCs that found on the research that has been done 


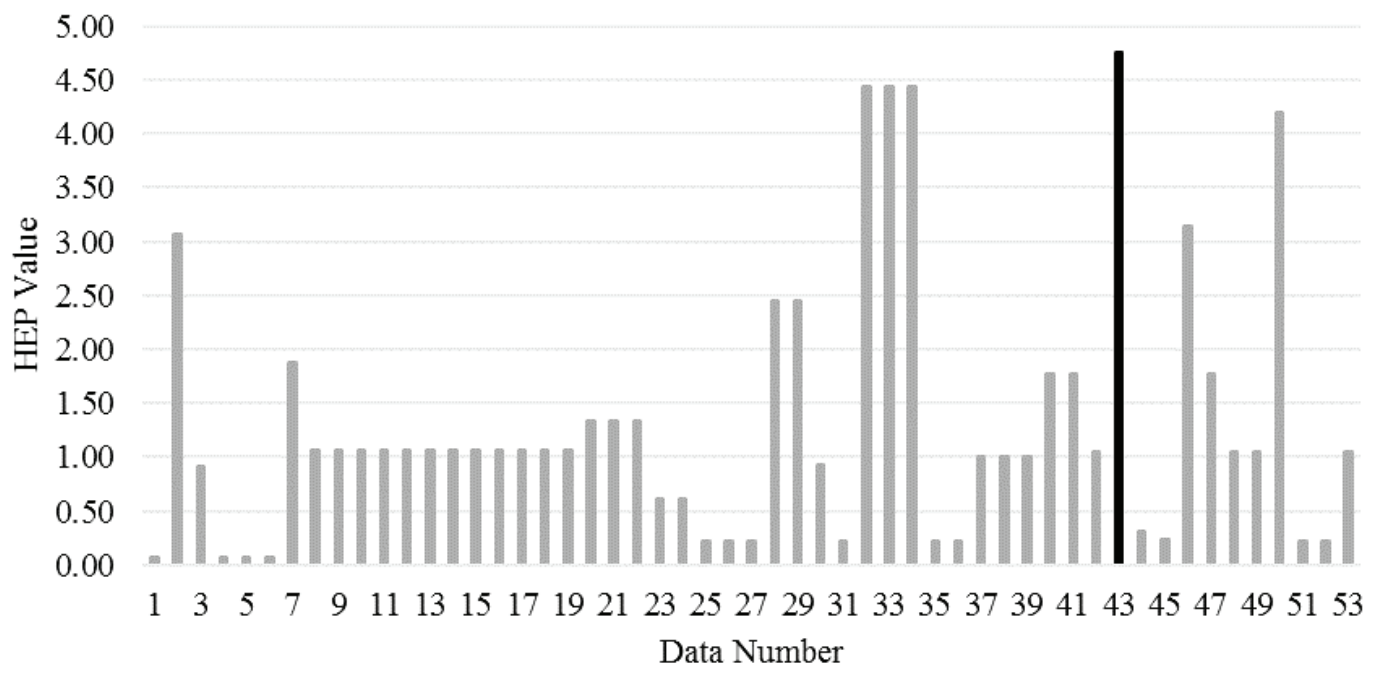

Figure 2: HEP Value of All Occupational Accidents Occurred In The Project.

were 24 out of $38 \mathrm{EPCS}$, with only 8 or $9 \mathrm{EPCs}$ that were frequently used in each case. Calculation result of HEP value using HEART method was shown on the Figure 2. The result showed that the $43^{r d}$ accident data generated the highest HEP value among other accidents.

\section{Discussion}

\subsection{Analysis of PSF-based risk assessment}

As mentioned in the results, PSF criteria number 2,5 , and 10 occurred in every task performed by workers. Criteria 2 indicated that in any task that was carried out in the project, there was no written SOP (both safety procedures and work procedures) that complete and be communicated to the workers in every task.

Criteria 5 showed that workers in the project did unsafe acts at any different stages of the work, such as not using personal protective equipment. Based on Reason [11], the occurring unsafe act could be classified as routine violation, which could occur because of the employers' indifference. According to Zaira and Hadikusumo [12], the presence of SOP and safety equipments were technical intervention which could directly affect workers' safety behavior.

Criteria 10 indicated that the occurrence of fatigue was experienced by workers in the project. This aspect could be seen from the overtime work to meet project deadline.

Based on the Table 1, in the unit of architectural work there were two types of work that belonged to the category IV risk (risk value of 24 ), which generated by fall from 
height hazard. Both works were performed by ironworkers. According to Nadhim et al. [13], ironworkers were one of worker groups that could be exposed by fall from height hazard.

The result showed that fall from height/ FFH hazards could generate high risk tasks in the project. Sorock et al. [14] stated that fall from height was the main cause of death by occupational accident in construction industry.

\subsection{Analysis of HEART}

The result shown on Figure 2 showed that the highest HEP value occurred on the $43^{\text {rd }}$ accident data, i.e. on installation of lightweight brick (including finishing process). The accident occurred when a worker fell from height of four meter. Zhang and Fang [15] stated that falls from height are common and serious accident type on construction sites. Hanapi et al. [16] also stated that falls from height still consistently have the highest rates amongst construction accidents compared with other types of accidents. At the time of the accident, the wood platform of scaffold used by the worker was broken and there was no any fall protection equipment available. Chi et al. [17] stated that the main cause of fall from scaffolds accident was the combination between improper use of the scaffolds and fall protection system.

Kirwan [18] stated that the HEART method involves error reduction strategies through EPCs. Based on the EPCs found, factors that contributed to the accident were unfamiliarity with a situation which is potentially important but which only occurs infrequently, no obvious means of reversing an unintended action, a mismatch between perceived and real risk which also stated by Fass et al. [19], an impoverished quality of information conveyed by procedures and person-person interaction which was very important $[20,21]$, an incentive to use other more dangerous procedures, unreliable instrumentation, and disruption of normal work-sleep cycles.

\subsection{Recommendations based on human error analysis}

Based on human error analysis performed, types of work that prioritized to be fixed by the recommendations were iron welding to steel columns or beams and the finishing process (architecture), which generated fall from height hazard. The implementation of health and safety recommendations in the project could be performed systematically, started from the employers, health and safety supervisor, and workers. 
Safety improvement recommendations could be started from the employers, as a manifestation of employers' commitment and implementation of company's safety policy and safety objectives. Various recommendations that needed to be done by the employers covered project organization structure renewal which separated health and safety supervisor duty from any unrelated function, creation of complete written procedures, provision of fall from height safety equipment, recruitment of workers who were competent in working at height, adjustment of workers' work cycle, improvement of safety culture at the site, provision of training particularly concerned with fall from height hazard, punishment against violation and appreciation for obedience of procedures, and sub-contractors hiring process based on safety issues [22].

Next recommendations were addressed to the project health and safety supervisor. The recommendations covered recording of any near miss and occupational accident and illness occurred, implementation of daily safety talk and weekly safety meeting consistently, and supervision of work especially related to the workers' compliance on implementing procedures.

Ultimately, the recommendations were addressed for iron welding and finishing workers particularly. The recommendations included the obligation to comply with the safety and work procedures to work at height, to implement daily safety talk among fellow workers to maintain risk perceptions and to prevent any dangerous practices, and to ensure the utilization of safety equipment's before performing iron welding and finishing process.

\section{Conclusions}

Based on the research conducted, it could be concluded that the highest risk potential occurred in installation of iron reinforcement from columns and beams work and concrete canopy work. The highest HEP value occurred in the fell from height accident suffered by architectural worker while installing the lightweight brick. The main cause of human error occurred in the ITB student dormitory building C and D construction project was the absence of complete written procedures for workers. Based on the analysis performed, it could be known that the company needed to improve the implementation of health and safety in the project, which could be done systematically. 


\section{Acknowledgement}

This study has been supported by the Faculty of Civil and Environmental Engineering, Institute of Technology Bandung. The authors would especially like to thank Mr. Tulus Eko as the project health and safety supervisor in the project.

\section{Competing interest}

The authors declare no conflict of interest.

\section{References}

[1] Amponsah-Tawiah K, Ntow MAO, Mensah J: Occupational Health and Safety Management and Turnover Intention in the Ghanaian Mining Sector. Safety and Health at Work 2016; 7: 12-17.

[2] De Felice F, Petrillo A, Carlomusto A, Ramondo A: Human Reliability Analysis: A review of the state of the art. International Journal of Research in Management \& Technology 2012; 2: 35-41.

[3] Sanders MM, McCormick EJ. Human Factors in Engineering \& Design, 7th ed. New York: McGraw-Hill; 1993.

[4] Awaludin A. Kajian Human Error pada Pekerja Subkon Sektor Jasa Konstruksi pada Proyek PT. B Tahun 2008 [unpublished thesis]. Universitas Indonesia; 2008.

[5] Lardner R, Scaife R: Helping engineers to analyse and influence the human factors in accidents at work. Process Safety and Environmental Protection 2006; 84: 179183.

[6] Moriyama T, Ohtani H: Risk assessment tools incorporating human error probabilities in the Japanese small-sized establishment. Safety Science 2009; 47: 1379-1397.

[7] Bell J, Holroyd J. Review of human reliability assessment methods. Derbyshire: Health and Safety Laboratory; 2009.

[8] Kirwan B: The validation of three Human Reliability Quantification techniques THERP, HEART, and JHEDI: Part 1 - Technique descriptions and validation issues. Applied Ergonomics 1996; 27: 359-373.

[9] Koradecka D. Handbook of Occupational Safety and Health. Boca Raton: CRC Press; 2010. 
[10] Kirwan B: The validation of three Human Reliability Quantification techniques THERP, HEART and JHEDI: Part III - Practical aspects of the usage of the techniques. Applied Ergonomics 1997; 28: 27-39.

[11] Reason J. Human Error. New York: Cambridge University Press; 1990.

[12] Zaira MM, Hadikusumo BHW: Structural equation model of integrated safety intervention practices affecting the safety behaviour of workers in the construction industry. Safety Science 2017; 98: 124-135.

[13] Nadhim EA, Hon C, Xia B, Stewart I, Fang D: Falls from Height in the Construction Industry: A Critical Review of the Scientific Literature. International Journal of Environmental Research and Public Health 2016; 13.

[14] Sorock GS, Smith EO, Goldoft M: Fatal occupational injuries in the New Jersey construction industry, 1983-1989. Journal of Occupational Medicine 1993; 35: 916921.

[15] Zhang M, Fang D: A cognitive analysis of why Chinese scaffolders do not use safety harnesses in construction. Construction Management and Economics 2013; 31(3): 207-222.

[16] Hanapi NM, Kamal MMM, Ismail MI, Abdullah IAK: Identifying Root Causes and Mitigation Measures of Construction Fall Accidents, Gading Business and Management Journal 2013; 17(1): 65-79.

[17] Chi C, Lin S, Dewi RS: Graphical fault tree analysis for fatal falls in the construction industry. Accident Analysis and Prevention 2014; 72: 359-369.

[18] Kirwan B. A Guide to Practical Human Reliability Assessment. London: CRC Press; 1994.

[19] Fass S, Yousef R, Liginlal D, Vyas P: Understanding causes of fall and struckby incidents: What differentiates construction safety in the Arabian Gulf region?. Applied Ergonomics 2017; 58: 515-526.

[20] Teo EAL, Ling FYY: Developing a model to measure the effectiveness of safety management systems of construction sites. Building and Environment 2006; 41: $1584-1592$.

[21] Shakioye SO, Haight JM: Modeling using dynamic variables-an approach for the design of loss prevention programs. Safety Science 2010; 48(1): 46-53.

[22] Rowlinson S. Construction Safety Management Systems. New York: Spon Press (Taylor and Francis Inc.); 2004. 